\author{
Cadernos de \\ ESTUDOS LINGǘlSTICOS - (54.1), Campinas, Jan./Jun. 2012
}

\title{
HESITAÇÕES NA FALA INFANTIL: INDÍCIOS DA COMPLEXIDADE DA LÍNGUA
}

\author{
LOURENÇO CHACON* \\ CRISTYANE DE CAMARGO SAMPAIO VILLEGA**
}

\begin{abstract}
RESUMO
O objetivo do presente estudo é identificar características do funcionamento das hesitações na produção oral de crianças com desenvolvimento típico de linguagem. O material foi extraído de gravações (individuais) em áudio de uma narrativa estruturada como uma parlenda por 26 crianças entre 5-6 anos de idade. Cinco juízes fizeram a identificação dos pontos de hesitação em cada gravação bem como das marcas com as quais as hesitações se mostraram: pausas silenciosas; repetições hesitativas; interrupções; e alongamentos hesitativos. Considerado o plano mais global da narrativa, $80,66 \%$ dos pontos de hesitação ocorreram em situações em que se combinavam mudanças: de estruturação rítmica dos versos; de posicionamento do narrador; e de tempo e modo verbais. Complementarmente, a estrutura interna dos versos em que se deram essas mudanças era construída com palavras de configuração fonológica complexa para os padrões de fala infantil. Os 19,34\% restantes de pontos de hesitação ocorreram em situações mais estáveis, tanto do ponto de vista da composição global da narrativa quanto da estrutura interna de seus versos. Esses versos caracterizavam-se por: repetição de estrutura rítmica; apresentação do conflito e do desfecho da narrativa; palavras de estrutura fonológica menos complexa para o vocabulário infantil. O aspecto não-casual, não-aleatório desses pontos reforça, portanto, a visão de que as hesitações indiciam negociações do sujeito com os outros constitutivos do (seu) discurso, já que ocorreram, privilegiadamente, em pontos nos quais co-ocorrências menos esperadas da própria língua se mostraram como um outro turbulento para as crianças.
\end{abstract}

Palavras-chave: hesitação; aquisição da linguagem; discurso.

\begin{abstract}
The aim of this study is to identify characteristics of hesitational functioning in speech productions of children with typical language development. The data were extracted from (individual) audio recordings of a short story structured as rimes by 26 children aged between 5-6 years old. Five judges made the identification of the points of hesitation in each recording and identified the brands in which the hesitations showed: silent pauses; repeting hesitations; interruptions; and hesitative elongations. Considering the global level of the narrative, $80.66 \%$ of the points of hesitation occurred in situations where changes were combined in: the rhythmic structure of the verses; the narrator's position; and in verbal tenses. In addition, the internal structure of the verses in which these changes occurred was built with words of complex phonological configuration for the patterns of children's speech. The 19,34\% remaining points of hesitation occurred in more stable situations, regarding the global composition

*. UNESP/FFC - Departamento de Fonoaudiologia. Marília (SP), Brasil. e-mail de contacto: lourencochacon@yahoo.com.br. Bolsista Pq/CNPq - Processo 304545/2009-0.

**. UNESP/FFC - Mestranda do Programa de Pós-Graduação em Fonoaudiologia. Marília (SP), Brasil. e-mail: cristyanesampaio@hotmail.com. Apoio FAPESP. Processo 2011/00429-1.
\end{abstract}


CHACON e VILLEGA - Hesitações na fala infantil: indícios...

of the narrative as well as the internal structure of its verses. These verses were characterized by: the repetition of rhythmic structure; the presentation of the conflict in the narrative and its outcome; less complex phonological structured words regarding the children's vocabulary. The non-random aspects of these points reinforce, thus, the idea that the hesitations exhibit points where the subject negotiates with the others constituents of (his) speech, once they occurred, privileged, in points where least expected language co-occurrences revealed themselves as a turbulent other to the children.

Key-words: hesitation; language acquisition; discourse

\section{INTRODUÇÃO}

O objetivo do presente estudo é identificar características do funcionamento das hesitações na produção oral de crianças com desenvolvimento típico de linguagem, especificamente na produção oral de uma parlenda.

Uma preocupação principal levou-nos a seu desenvolvimento: aprofundar o diálogo entre Linguística e Fonoaudiologia, em particular no que se refere à investigação que esses dois campos de conhecimento desenvolvem sobre as questões de fluência e de aquisição da linguagem. Visamos contribuir para esse diálogo apresentando resultados obtidos a partir de uma visão lingüístico-discursiva das hesitações na aquisição da linguagem.

Para a Fonoaudiologia, a contribuição mais esperada é justamente chamar a atenção para essa visão, no que diz respeito às questões da fluência/disfluência. Com efeito, a visão que prevalece nesse campo é a da gagueira de fundo multigênico ou neurogenético, segundo a qual a gagueira decorreria de uma condição cuja etiologia é multifatorial - visão que possibilita pouco espaço para a observação de como os sujeitos se marcam e deixam indícios de sua relação com a complexidade da língua ao falarem. Para a Linguística, acreditamos que a principal contribuição seja justamente a de privilegiar a ótica lingüístico-discursiva no estudo do funcionamento das hesitações na aquisição da linguagem. Mas este estudo pretende também contribuir para a compreensão das formulações constitutivas da fala infantil, possibilitando, assim, avançar em conhecimentos teóricos que propiciem uma melhor compreensão das instabilidades na aquisição da linguagem.

As hesitações vêm sendo bastante mencionadas - embora não como principal objeto de investigação - em trabalhos desenvolvidos por pesquisadores brasileiros no campo da Fonoaudiologia. São várias as visões sobre as hesitações nesse campo.

Em sua maioria, os estudos que mencionam as hesitações relacionam-nas a condições patológicas (como a gagueira) ou a comparações entre o que é tido como típico e como patológico na linguagem - especialmente em seu processo de aquisição. Exemplos dessas preocupações encontram-se em Lemos e Chiari (1995), Degiovani et al (1999), Andrade (2000, 2002a e 2002b), Faria e Ferriolli (2005), Merçon e Nemr (2007), Oliveira et al (2007) e Martins e Andrade (2008). Da perspectiva adotada nesses estudos, ao se compararem as disfluências tidas como comuns a todos os falantes e aquelas consideradas como mais típicas de sujeitos gagos, melhor se distinguiria o que é considerado normal do que pode ser considerado como patológico nas questões de fluência/disfluência - nelas, incluídas as hesitações. 
Distinguindo-se dessa visão - majoritária - das hesitações, investigações de pesquisadores fonoaudiólogos brasileiros têm se ocupado das hesitações com outras preocupações. São preocupações bastante variadas, como veremos a seguir.

No campo bastante específico da resolução de conflitos, por exemplo, Befi-Lopes e Paula (2008) se preocupam em investigar em que medida a resolução de conflitos em crianças em idade escolar se relacionaria com a ocorrência das chamadas disfluências comuns. Orienta essa investigação a ideia de que, para essa resolução “(...) é preciso compreender o ponto de vista do outro, assim como desenvolver e expressar estratégias para resolver disputas." (BEFI-LOPES e PAULA, 2008, p. 272).

Em Friedman (1986), as hesitações aparecem no contexto de relações que a autora estabelece entre subjetividade e gagueira. O gago, para a autora, tem, como característica de sua identidade, auto-imagem de mal falante. Essa auto-imagem resultaria de situações de comunicações paradoxais criadas pelos pais, na medida em que ignorariam o fato de o comportamento disfluente ser normal em crianças, gerando nelas insegurança ao falar, o que poderia conduzir à disfluência. Essa situação levaria a uma

subjetividade marcada pela visão estigmatizada de si como falante, que veio a se constituir por meio de relações de comunicação em que a repetição e a hesitação na fala são vistas como receio, negativismo, como não aceitação [de si mesmo]. (FRIEDMAN, 1986, p.132).

Com essa mesma visão, Silveira (1989) propõe avaliar a fluência de fala, buscando compreender não só a manifestação articulatória do gago, mas também a relação dessa manifestação com o movimento de sua consciência, por meio da análise do conteúdo do seu discurso sobre a fala. Para Silveira, sua preocupação se justifica pelo fato de que o padrão determinado socialmente (a fala sem hesitação) gera no individuo emoções negativas, fazendo com que o indivíduo faça força para falar bem.

Schiefer et al (1992), em estudo que relata a experiência de orientação a pais com o objetivo de tentar prevenir que rupturas da fala se tornem gagueiras, elaboram um guia no qual explicam que a quebra da fluência é uma dificuldade que pode afetar a criança no início da aquisição de linguagem. As autoras destacam que a criança, quando começa a falar, não possui a fluência normal do adulto, passando por uma fase de disfluência nesse aprendizado. Assim,

enquanto [a criança] fala, às vezes, hesita na escolha das palavras, repete ou prolonga os sons (...) ou não os pronuncia corretamente. Essas inadequações são inerentes e naturais ao processo normal de desenvolvimento, uma vez que a criança progressivamente, passa a ter domínio motor da fala, bem como das regras da língua (SCHIEFER ET AL, 1992, p.03).

As autoras concluem que a pressão psicológica feita pelos pais, quando percebem a aparição de hesitações na fala da criança, pode gerar uma intervenção no processo de aquisição, ocasionando a gagueira. 
Em outro trabalho, Friedman (1999) faz uma reflexão crítica sobre o que é considerado como normal ou normativo comparado com o que é considerado como patológico em termos de fluência. Com base em pesquisas sobre o cotidiano da produção da fala, a autora conclui que não há como, de forma científica, fixar previamente padrões virtuais de fluência e disfluência como normais e patológicos para nortear os processos de avaliação, orientação e tratamento da fala.

Barros e Friedman (2000) analisam a narrativa de autores que definem a normalidade e a patologia quanto à produção de fala. Na conclusão desse estudo, as autoras destacam:

a fala é um processo espontâneo: não se sabe como se fala, apenas se sabe falar, e nesse contexto surgem não apenas gagueiras, mas atos-falhos, falhas de evocação (...) não existe um sujeito que nunca perde o controle sobre sua própria fala, sendo isto algo natural ao falar (BARROS e FRIEDMAN, 2000, p. 337).

Por fim, no que mais diretamente diz respeito à contribuição das investigações linguísticas para aquelas desenvolvidas no campo da Fonoaudiologia, um estudo merece destaque: o de Ferriolli (2002). Nesse estudo, a autora relata a história de um adulto de 33 anos de idade, com queixa de gagueira, interpretando-a com base em contribuições da análise do discurso de filiação francesa. O destaque que fazemos a esse estudo se deve não apenas à proposta da autora, mas, sobretudo, à conclusão a que ela chegou: a da eficácia de se instaurar uma possibilidade discursiva no estudo das disfluências de fala.

A possibilidade de um olhar discursivo para as questões de fluência/ disfluência, embora bastante singular e restrita no contexto da Fonoaudiologia no Brasil, já vem mostrando sua eficácia no que se refere à pesquisa sobre o funcionamento das hesitações em sujeitos com Doença de Parkinson, por exemplo. A título de exemplo, uma visão discursiva das hesitações orienta o desenvolvimento de trabalhos como os de Nascimento (2005 e 2010), Nascimento e Chacon (2006 e 2011) e Vieira (2009), dentre outros - todos eles desenvolvidos no interior do Grupo de Pesquisa Estudos sobre a linguagem (GPEL/CNPq).

No GPEL, as hesitações têm sido consideradas como marcas das negociações do sujeito com os outros constitutivos do (seu) discurso. Privilegiadamente, o outro constitutivo para o qual as investigações do GPEL têm se voltado é a própria língua, em sua complexidade. Também será esta a visão com que olharemos, neste trabalho, para as hesitações: como marcas da negociação - muitas vezes problemática - do sujeito com a língua, enquanto outro fundamental da sua constituição como sujeito (falante).

\section{MATERIAL E MÉTODO}

Os dados foram extraídos de amostras de fala que integram o projeto Instabilidades na constituição e nos sintomas de linguagem (aprovado pelo CEP/FFC sob o número 138/2010), coordenado por Lourenço Chacon. Esse banco consiste não somente de gravações de caráter mais experimental de todo o sistema fonológico 
do Português Brasileiro, como também de gravações de caráter mais espontâneo ou mais controlado feitas com crianças de ambos os gêneros (com idade entre três a seis anos). A sede do projeto é a Escola Municipal de Educação Infantil Sítio do Pica-pau Amarelo, localizada em Marília (SP).

Para a realização do presente estudo, foram selecionadas apenas gravações de caráter mais controlado, de 26 crianças (identificadas como C01, C02... C26), entre cinco e seis anos de idade. A escolha por esse tipo de material decorreu da preocupação em detectar quais pontos, de um mesmo material linguístico, se mostrariam como turbulentos para um grupo mais homogêneo de crianças - e que, portanto, melhor indiciariam negociações possivelmente mais conflitantes da criança com a complexidade da língua.

As gravações foram feitas com cada criança individualmente, no interior de uma cabine acústica instalada na instituição de coleta, com uso de equipamentos de alta fidelidade: um gravador digital MARANTZ (modelo PMD 670) acoplado a um microfone cardióide dinâmico SHURE (modelo 8800). Para as gravações dos sujeitos do presente trabalho, foi solicitada de cada uma das 26 crianças, individualmente, a reprodução da parlenda A Formiguinha, trabalhada previamente em sala de aula pela professora (como parte do planejamento pedagógico da escola da coleta) e memorizada pelas crianças. Segue-se o texto da parlenda:

Formiguinha da roça endoideceu,

Com uma dor de cabeça que the deu.

Ai, pobre forminha,

Põe a mão na cabeça

E faz assim,

E faz assim.

Após o trabalho em sala de aula, foram realizadas as gravações em áudio no interior da cabine acústica, que consistiram de um registro por criança, sem que a criança pudesse refazê-lo.

Para a caracterização das marcas de hesitação encontradas nas amostras de fala das crianças, foram utilizadas classificações de marcas hesitativas encontradas em trabalhos de Marcuschi (1999), Nascimento (2005) e Vieira (2009), a saber: (i) pausas silenciosas; (ii) alongamentos hesitativos; (iii) repetição hesitativa; (iv) interrupções. ${ }^{1}$

Uma vez identificados - numa primeira análise de outiva feita por um dos autores do presente trabalho - os pontos de hesitação e caracterizadas suas marcas,

1. Pausas silenciosas $=$ percebidas, auditivamente, como silêncios, prolongados ou não, que se dão como rupturas em lugares não previstos pela sintaxe; alongamentos hesitativos = aumento de duração de segmentos da fala, geralmente dos segmentos vocálicos em final de palavra e principalmente em palavras monossilábicas ou em silabas finais átonas; repetições hesitativas = reduplicações de uma silaba, de palavras, de grupos de palavras ou de frases, podendo essas reduplicações incidir tanto sobre itens funcionais quanto sobre itens lexicais; interrupções = cortes após a emissão de qualquer segmento lingüístico, seja ele fonético-fonológico, lexical ou sintático, podendo ser retomado ou não na seqüência da produção do enunciado (VIEIRA, 2009). 
cada um dos arquivos de gravação das crianças foi apresentado para um grupo de cinco juízes, composto por integrantes do GPEL e bastante familiarizados com o trabalho com hesitações desenvolvido no interior desse grupo de pesquisa. Antes da apresentação das gravações aos juízes, foi-lhes dada instrução quanto às categorias utilizadas para caracterizarem as marcas de hesitação. A produção de cada criança foi transcrita sem nenhuma das marcas de hesitação identificadas na análise de outiva e sem nenhum sinal de pontuação. De posse das transcrições, os cinco juízes escutaram as produções das crianças e anotaram, com base nas instruções prévias, os pontos em que julgaram haver hesitações nas produções. Além de identificarem esses pontos, os juízes também anotaram as marcas com que as hesitações se mostraram para eles. Adicionalmente, quando os juízes relataram dúvidas quanto à caracterização das marcas, as gravações foram apresentadas a eles uma segunda vez. Com base nos registros dos pontos e das marcas de hesitação pelos juizes, foi calculado o grau de concordância entre seus registros, adotando-se o critério de concordância de $80 \%$ como parâmetro para o estabelecimento de consistência do julgamento. Trata-se de índice considerado como de alta significação em análises estatísticas (BATISTA, 1977; GELAMO, 2006).

\section{EXPOSIÇÃO DOS RESULTADOS}

Com base numa concordância de, no mínimo, 80\%, primeiramente organizamos a distribuição das marcas linguísticas de hesitação, em função da quantidade com que ocorreram no conjunto das produções analisadas. Esses números foram, em seguida, organizados de acordo com seu percentual de ocorrência. Os dados relativos a essa distribuição e respectivo percentual encontram-se na Tabela 1:

Tabela 1. Distribuição e percentual das marcas de hesitação.

\begin{tabular}{lcc}
\hline Tipo de marca & Quantidade & Porcentagem \\
\hline Pausa silenciosa & 17 & $45,9 \%$ \\
Repetição hesitativa & 14 & $37,9 \%$ \\
Interrupções & 05 & $13,5 \%$ \\
Alongamento hesitativo & 01 & $2,7 \%$ \\
\hline Total & $\mathbf{3 7}$ & $\mathbf{1 0 0 \%}$ \\
\hline
\end{tabular}

Seguem-se exemplos de ocorrências das diferentes marcas de hesitação:

- pausa silenciosa (\#): Formiguinha da roça en\#doideceu - C17;

- repetição hesitativa: Ai probe probe probe - C13;

- interrupção (/): Ai pó/ pobre formiguinha - C23;

- alongamento hesitativo (:): Faz as::sim - C02. 
Cadernos de Estudos Lingǘlsticos (54.1) - Jan./Jun. 2012

Por fim, organizamos os pontos que os juízes perceberam como de hesitação. Nessa organização, dispusemos a distribuição e a quantidade desses pontos em função dos versos do texto da parlenda, como se verá na Tabela 2:

Tabela 2. Distribuição e quantidade dos pontos de hesitação.

\begin{tabular}{lc}
\hline Locais de ocorrências & Quantidade \\
\hline Formiguinha da roça endoideceu & 02 \\
Com uma dor de cabeça que lhe deu & 01 \\
Ai pobre formiguinha & 16 \\
Põe a mão na cabeça & 09 \\
E faz assim e faz assim & 03 \\
Total & $\mathbf{3 1}$ \\
\hline
\end{tabular}

Seguem-se exemplos de pontos de hesitação em cada um dos versos da parlenda:

Formiguinha da rosa enlorde\#ceu - C06;

Com uma dor de cabeça que me \#deu-C11;

Ai pobre \# pobre formiguinha-C04;

Põe a mão na cabe\#ça-C07;

Ef\#az assim - C09.

Comparadas as quantidades expostas na Tabela 1 (37) e na Tabela 2 (31), observa-se maior quantidade de marcas hesitativas do que de pontos em que ocorreram essas marcas. Em cada ponto de hesitação, os juízes detectaram, mais recorrentemente, apenas uma das quatro marcas de hesitação identificadas no material em análise - relembrando: pausa silenciosa, repetição hesitativa, interrupção e alongamento hesitativo. Em outras palavras, em geral, nos pontos de hesitação, foram detectadas marcas simples (ou seja, para cada ponto, uma marca). Em seis desses pontos, no entanto, foram detectadas marcas combinadas, isto é, neles, duas ou mais marcas lingüísticas se mostraram associadas a uma mesma ocorrência de hesitação (por exemplo: uma repetição + uma pausa silenciosa, uma interrupção + uma pausa silenciosa etc.).

Em síntese, foram identificados 31 pontos de hesitação, indiciados por marcas simples e por marcas combinadas. Na Tabela 03, são expostos os resultados dessa distribuição:

Tabela 3: Distribuição numérica e percentual das marcas simples e das marcas combinadas

\begin{tabular}{l|l}
\hline Marcas hesitativas & Quantidade \\
\hline Marcas simples & $25(81 \%)$ \\
Marcas combinadas & $06(19 \%)$ \\
\hline Total & $31(100 \%)$ \\
\hline
\end{tabular}


CHACON e VILLEGA - Hesitações na fala infantil: indícios...

Seguem-se exemplos dessa subdivisão:

Ai probe probe probe formiguinha, como exemplo de marca simples, em que a ocorrência de hesitação é mostrada por uma marca hesitativa (simples) de repetição - $\mathrm{C} 03$;

Ai ai \# pobre formiguinha, como exemplo de marca combinada, em que a ocorrência de hesitação é mostrada por uma marca hesitativa (combinada) de repetição + pausa silenciosa $-\mathrm{C} 25$.

Passemos, neste ponto, a discutir as tendências para as quais os resultados apontam.

\section{DISCUSSÃO DOS RESULTADOS}

Observando os dados dispostos na Tabela 1, chama-nos a atenção a diversidade e a distribuição das marcas de hesitação. De acordo com a distribuição com que as marcas de hesitação foram percebidas pelo conjunto dos juízes, a pausa silenciosa foi a marca que apresentou maior percentual de ocorrência (45,9 \%), seguida da repetição hesitativa $(37,9 \%)$, da interrupção $(13,5 \%)$ e do alongamento hesitativo $(2,7 \%)$.

Essa distribuição nos sugere, primeiramente, que as crianças já se mostram sensíveis à diversidade de recursos lingüísticos com que a própria língua permite, ao sujeito, hesitar. Sugere-nos também - pelo menos no que diz respeito aos dados que obtivemos - que há recursos preferenciais pelos quais as crianças mostram seus momentos de conflito com a complexidade da língua, a saber, as pausas silenciosas e as repetições hesitativas.

Nesse sentido, os recursos preferenciais pelos quais as crianças mostraram seus conflitos diferenciam-se daqueles com que os adultos os mostram. Com efeito, tanto em processos não-patológicos (MARCUSCHI, 1999), quanto em processos considerados como patológicos (NASCIMENTO, 2005 e 2010; NASCIMENTO E CHACON, 2006; VIEIRA, 2009), os adultos tendem a mostrar em sua fala uma diversidade maior de tipos de marcas de hesitação e de preferências no que se refere às marcas que selecionam (não necessariamente pausas silenciosas e repetições hesitativas). Fica por confirmar, em trabalhos posteriores, se a pouca diversidade de marcas encontradas nos dados se deve ao tipo de produção lingüística analisada (uma parlenda memorizada), ao grupo de crianças analisado, ou se seria, mesmo, característica da linguagem infantil.

Chama-nos, ainda, a atenção, nos resultados, a relação entre pontos de ocorrência/quantidade de marcas hesitativas. Retomando os dados da Tabela 3, em $81 \%$ desses pontos foram identificadas marcas simples, e em 19\%, marcas combinadas de hesitação. Essa grande diferença percentual em favor das marcas simples provavelmente se deve ao fato de as crianças terem produzido um texto em verso e previamente decorado. 
Há, na verdade, dois aspectos da memorização que se sobrepõem nesse caso. Por um lado, observa-se o caráter formulaico do verso, resultante de sua combinação linear de características repetidamente evocadas como recursos de memorização. Por outro lado, o treino para decorar explora, por meio de seguidas repetições, essas características do verso. Esses dois aspectos ligados à memorização podem ter determinado a redução da variedade de marcas e o uso predominante de marcas simples.

Assim, essas características da produção contribuíram, possivelmente, não só para que, em 26 produções, fossem detectados somente 31 pontos de hesitação (ou seja, uma média de 1,19 por criança), mas também para que, nesses pontos, linguisticamente, apenas uma marca hesitativa ocorresse. Destaque-se, a propósito, que, dos seis pontos de marcas combinadas, cinco deles corresponderam a momentos de correção de uma estrutura, como Põe na/\#põe a mão na tabeça (em que se combinam a interrupção seguida de pausa silenciosa) e Ai probrel pobre formiguinha (em que se combinam a repetição hesitativa e a interrupção). Essa regularidade de funcionamento (83,33\% das seis ocorrências) explicaria, portanto, o caráter de exceção que as marcas combinadas assumiram no material em análise.

Por fim, uma última tendência dos resultados chamou-nos, particularmente, a atenção. Para discuti-la, retomemos os dados expostos na Tabela 2, que trata dos locais da parlenda em que ocorreram hesitações; lembremos, também, que a parlenda é estruturada como uma pequena narrativa em versos.

Comecemos, então, pela discussão dos pontos de hesitação detectados nos dois primeiros versos da parlenda: Formiguinha da roça endoideceu $=2$ pontos; Com uma dor de cabeça que lhe deu $=1$ ponto. São apenas três ocorrências nesses dois versos $(9,67 \%)$, do total de 31 ocorrências (100\%). O que justificaria esse baixo percentual de ocorrência no conjunto de produções das crianças?

Em primeiro lugar, esses dois versos se caracterizam pela repetição de uma regularidade rítmica e sonora - são dois versos decassílabos em sequência, com proeminências nas suas terceira, sexta e décima sílabas, rimados em seu final. Caracterizam-se, ainda, em termos semânticos, por, ao mesmo tempo, apresentarem uma personagem e seu conflito. Caracterizam-se, finalmente, pela presença de verbos no passado, numa disposição muito próxima daquela verificada comumente em narrativas infantis tradicionais, iniciadas com Era uma vez, nas quais se conta um fato que já aconteceu. Esse conjunto - co-ocorrente - de regularidades justificaria, a nosso ver, o baixo percentual de ocorrências de hesitação na produção dos dois primeiros versos da parlenda pelo conjunto de crianças.

Há que se ressaltar a presença, nos dois primeiros versos, de duas palavras polissilábicas (formiguinha e endoideceu) - palavras que, por sua extensão, poderiam provocar turbulências em sua produção por parte das crianças. No entanto, como vimos, apenas 03 ocorrências de hesitação foram detectadas nesses versos. Um aspecto que parece ter minimizado a possibilidade de ocorrência de hesitações especialmente na palavra endoideceu (fonologicamente mais complexa do que formiguinha, já que apresenta padrão rítmico menos frequente no léxico do português - o iambo, característico das palavras oxítonas -, bem como estruturas 
CHACON e VILLEGA - Hesitações na fala infantil: indícios...

silábicas menos comuns - en, doi e ceu - com coda, ou seja, com ramificação da rima silábica) é o de que essa palavra ocorre em situação de rima com a palavra $d e u$, no verso seguinte - o que pode ter contribuído para que fosse produzida praticamente sem hesitações.

Situação bastante diferente se observa nos pontos de hesitação detectados nos dois versos seguintes da parlenda: $A i$, pobre formiguinha $=16$ pontos; Põe a mão na cabeça $=9$ pontos. Como se pode verificar, dos 31 pontos de hesitação (100\%), os 16 que ocorreram no primeiro desses dois versos correspondem a $51,61 \%$ e os 9 do segundo correspondem a $29,03 \%$ - somando, portanto, $80,64 \%$ dos pontos de hesitação. Não nos parece casual, como procuraremos demonstrar, que justamente nesses dois versos se concentrem $80,66 \%$ das ocorrências de hesitação.

Vejamos. O terceiro verso inicia uma mudança de direção rítmica na parlenda, que se estende para o quarto verso. Como vimos, os dois primeiros eram decassílabos e rimavam em seu final. Já o terceiro e o quarto versos são hexassílabos, apresentam proeminências em diferentes posições rítmicas (segunda e sexta sílabas, no terceiro; primeira, terceira e sexta sílabas, no quarto) e não rimam entre si - aliás, rimas ocorrem somente entre o primeiro e o segundo versos da parlenda.

Uma complexa mudança semântica também se inicia no terceiro verso, introduzida pela interjeição $A i$. Inicia-se, aí, uma mudança de posição do narrador, que se estenderá até o final da parlenda. Com efeito, a partir desse ponto, o narrador não mais expõe um conflito; mais do que expor, ele passa a comentar o conflito já exposto. No entanto, é dúbia a interpretação que se pode ter desse comentário. Por um lado, numa primeira interpretação, é possível pensar que esse comentário seria, na verdade, um diálogo que se abre entre o narrador e a personagem formiguinha - colocada na posição de interlocutor, marcado pelo vocativo pobre formiguinha. Mas, por outro lado, é possível pensar que esse comentário não caracterizaria um diálogo com a personagem formiguinha, mas, sim, uma demonstração de adesão do narrador à sua dor. Nessa segunda interpretação, o narrador se marcaria, portanto, como um expectador que compartilha do evento narrado. De qualquer modo, em relação aos dois primeiros versos da parlenda, o terceiro e o quarto versos se mostram semanticamente mais complexos, dada a ambiguidade com que se apresentam à interpretação e a desestabilização que provocam em relação à direção com que vinha se construindo a narrativa na parlenda.

Uma terceira mudança (além da rítmica e da semântica) também se mostra nesses dois versos: a mudança do tempo e do modo verbais. Essa dupla mudança parece ter como corolários: (1) uma desestabilização da estrutura temporal clássica das narrativas infantis (construídas, predominantemente, no tempo passado), já que presentifica o evento narrado no passado - a história aconteceu, ou ainda está acontecendo?; e (2) uma desestabilização no modo como o narrador constrói a narrativa - ele não apenas observa, como nas narrativas infantis mais tradicionais; ele também comenta. Aliada à mudança rítmica da parlenda, essa mudança modotemporal acaba por provocar uma possível perplexidade do olhar infantil para o funcionamento da linguagem, justamente por escancarar sua descontinuidade, seu caráter não-homogêneo, sua não-satisfação de expectativas pré-construídas. 
Cadernos de EsTUDOS Lingǘlsticos (54.1) - Jan./Jun. 2012

Além da contribuição desses aspectos - digamos - mais globais da narrativa para a grande quantidade de hesitações nesses dois versos (recordemos: 80,66\% das ocorrências), aspectos mais específicos de sua estrutura interna parecem tornálos ainda mais complexos para sua enunciação por parte das crianças. Com efeito, no verso $A$, pobre formiguinha a palavra pobre se destaca por sua organização fonológica: é composta de uma silaba simples de baixa complexidade (CV) na posição acentuada, seguida de uma silaba com padrão silábico complexo (CCV) em posição não-acentuada, ou seja, maior complexidade fonológica da sílaba justamente na posição mais fraca do português brasileiro - a pós-tônica final. Essa complexidade se torna maior pelo fato de ocorrer em enunciados de crianças com 5-6 anos de idade, em processo de "congelamento" dessas estruturas (SCARPA, 1995).

Destaque-se, ainda, que a complexidade fonológica da palavra pobre fica mais em evidência pelo fato de essa palavra se combinar com outra que é polissilábica (formiguinha), quantidade silábica não-usual no vocabulário infantil. Resulta, pois, dessa combinação uma estrutura complexa e rara nesse vocabulário: pobre formiguinha.

Também chamam a atenção no verso Põe a mão na cabeça características fonológicas que, às crianças, podem se mostrar como complexas. Trata-se, num mesmo verso, da recorrência de elementos nasais (em põe, mão e $n a$ ), de consoantes com bloqueio total de articuladores $(p, m, n, k$ e $b)$, preferencialmente articuladas na região labial $(p, m$ e $b)$. Essa tríplice combinação de movimentos repetidos pode se mostrar como problemática para um conjunto significativo de crianças; desse modo, rupturas nessa estrutura funcionariam, na verdade, como momentos de desarticulação de uma - talvez incômoda e difícil - recorrência motora.

Assim, além das mudanças mais globais da narrativa que se iniciam nesses dois versos, características de sua estrutura interna (como as de natureza fonológica e motora) colaboram para o elevado número de hesitações que ocorrem em sua produção pelas crianças. Ressalte-se mais um indício da ação desse conjunto de complexidades na produção das crianças: todas as seis marcas combinadas de hesitação ocorreram justamente na produção desses dois versos. É, portanto, a complexidade da linguagem - mais fortemente evidenciada no terceiro e no quarto versos da parlenda - que se indicia nas ocorrências de hesitação desse conjunto das crianças.

Um último aspecto a ser levantado a propósito desses dois versos é o da relação intersemiótica verbal/gestual posta em prática a partir do verso Põe a mão na cabeça: o narrador/comentador passa também a atuar, dramatizando a ação. Instaura-se, assim, uma complexidade semiótica, que interliga narração, comentário e atuação. Nessa complexização do ato de narrar, intensificada com a dramatização do ato narrado, o sujeito (enquanto pessoa - DUCROT, 1987), a própria criança, parece, pois, se identificar com a figura textual do narrador, que, por sua vez, assimila seu ponto de vista ao da personagem (a formiguinha em seu sentimento de dor).

Resta comentarmos o baixo percentual de ocorrências de hesitação nos últimos versos da parlenda: E faz assim / E faz assim. São apenas três (9,66\% do total). 
Do ponto de vista rítmico, mais uma mudança ocorre: de hexassílabos, os versos passam a tetrassílabos. No entanto, a repetição exata de uma mesma estrutura ( $E$ faz assim) tende a diluir o efeito dessa mudança, fato que a baixa quantidade numérica e percentual de hesitações parece indiciar. Do ponto de vista semântico, também se verifica uma mudança: nesses versos, o narrador propõe um desfecho para o conflito. Uma mudança semântica em direção a uma solução, a um final, marcada, além disso, pelo juntor (no caso) conclusivo $e$, parece, pois, resgatar uma característica que pode soar como familiar às crianças, pelo seu contato cotidiano com histórias infantis tradicionais em seu ambiente escolar. Eis, provavelmente, mais uma razão para a baixa ocorrência de hesitações nesses dois últimos versos. Ressalte-se, ainda, que se trata de um desfecho cuja ação não é descrita verbalmente, mas apenas gestualmente, complementando a enunciação de signos (vazios) que remetem diretamente a um movimento de pressionar a cabeça com as duas mãos que as crianças deveriam fazer ao enunciá-los ( $E$ faz assim / E faz assim). Destaque-se, por fim, a relativamente baixa complexidade estrutural com que o desfecho é construído - uma vez que ele é composto de apenas três palavras, bastante comuns (e não apenas no vocabulário infantil) e de pouca complexidade fonológica, já que duas são monossilábicas e uma dissilábica. Nelas, além disso, os padrões silábicos mais complexos - faz e sim (CVC) - estão presentes em posições acentuadas. Como se vê, diferentemente de como co-ocorreram os diferentes aspectos da linguagem no terceiro e quarto versos da parlenda, no quinto e sexto, a co-ocorrência se mostrou muito menos turbulenta para as crianças - fato que a grande diferença percentual de ocorrência de hesitações naqueles e nestes versos parece indiciar. Finalmente, do ponto da relação intersemiótica, cabe, nesse caso, ao gesto o comentário. O elemento dêitico “assim” é, pois, preenchido semanticamente pelo gesto, resultando numa elocução essencialmente icônica, em que se interligam características verbais e gestuais.

\section{CONSIDERAÇÕES FINAIS}

Foram identificados, em nossos dados, 31 pontos de hesitação, indiciados por marcas simples e combinadas, em um grupo de 26 crianças - o que equivale a uma média de 1,19 ocorrências de hesitação por criança (31 pontos / 26 crianças $=1,19)$. Esse resultado poderia ser interpretado como, de certo modo, previsível: uma vez que analisamos a produção de uma parlenda, estruturada em versos e previamente memorizada pelo grupo de crianças, poder-se-ia até mesmo esperar uma total ausência de ocorrências de hesitação.

No entanto, quando observamos os pontos da produção da parlenda em que preferencialmente ocorreram as hesitações, chamou-nos particularmente a atenção a regularidade desses pontos no conjunto das crianças. O aspecto não-casual, nãoaleatório desses pontos reforça, portanto, nossa visão sobre o funcionamento das hesitações: elas indiciam negociações do sujeito com os outros constitutivos do (seu) discurso. Pelo menos no recorte de observação que fizemos, as hesitações ocorreram, privilegiadamente, em pontos nos quais co-ocorrências menos 
Cadernos de Estudos Lingǘlsticos (54.1) - Jan./Jun. 2012

esperadas da própria língua se mostraram como um outro turbulento para as crianças. Assim, além de exibir pontos menos ajustados da ordem da língua, as hesitações exibiriam "pontos em que o sujeito se revela" (SCARPA, 1995, p. 179), já que ele se mostra ao mostrar os desajustes da língua.

Scarpa (1995) chama, ainda, a atenção para o fato de que os fragmentos de fala que se consideram como fluentes correspondem àqueles que já se mostram como congelados para a criança. Trata-se, pois, daquelas estruturas da língua, produzidas nesses fragmentos, que mais se mostram como ajustadas para a criança. As hesitações na fala infantil mostrariam, portanto, o "descongelamento" de estruturas, ou, em sentido mais amplo, a indagação (da criança) sobre a própria configuração de uma estrutura que é, ela mesma, instável em sua constituição: a língua.

Como observação final, o funcionamento dêitico de "assim" nos dois últimos versos, mais próximo de uma forma congelada (por se tratar de um signo vazio em relação icônica com o gesto), contrasta com a relação entre gesto e palavra no antepenúltimo verso, "Põe a mão na cabeça", em que o gesto não se relaciona a um signo vazio. Neste caso, portanto, o grande percentual de hesitação marcaria não apenas co-ocorrências menos esperadas da própria língua, mas também uma co-ocorrência verbal/gestual não-previsível justamente num momento em que descrever e interpretar o dizer reforçam/promovem uma ambigüidade narrativa.

\section{AGRADECIMENTOS}

Nosso agradecimento aos professores Arnaldo Franco Júnior e Manoel Luiz Gonçalves Corrêa, pela generosidade da leitura da primeira versão deste artigo e pelas valiosas contribuições de ambos para a versão final. Nosso agradecimento, também, à cuidadosa leitura que fizeram os dois pareceristas que analisaram o presente artigo. Obviamente, falhas que restam são de nossa responsabilidade.

\section{REFERÊNCIAS BIBLIOGRÁFICAS}

ANDRADE, C. R. F. (2000). Processamento da fala: aspecto da Fluência. Revista Pró-Fono, Barueri, v.12, n.1, p. 67-71.

. (2002a). História natural da gagueira - estudo I: perfil da fluência. Revista Pró-Fono, Barueri, v.14, n.3, p 351-360.

(2002b). História natural da gagueira - estudo III: vocabulário, fonologia e pragmática. Revista Pró-Fono, Barueri, v.14, n.3, p 371-382.

BARROS, R.P.; FRIEDMAN, S. Concepções sobre fluência: ideologias subjacentes. Distúrbios da Comunicação. São Paulo, v.12, n.2, 2000.

BATISTA, C. G. (1997). Concordância e fidedignidade na observação. Psicologia, v. 3, n.2, 39-49, jul.

BEFI-LOPES, D.; PAULA, E. M. (2008). Habilidades de resolução de conflito e ocorrência de disfluências comuns em crianças em desenvolvimento normal de linguagem. Revista da Sociedade Brasileira de Fonoaudiologia, v.13, n.3. 
CHACON e VILLEGA - Hesitações na fala infantil: indícios...

DEGIOVANI, V. M.; CHIARI, B. M.; SCHIEFER, A. M. Disfluência: caracterização dos tipos e freqüência de ocorrência em um grupo de escolares. Revista Pró-Fono, v.11, n.1, p.32-41, 1999

DUCROT, O. (1987). O dizer e o dito. Campinas: Pontes.

FARIA, A. A.; FERRIOLLI, B. H. V. M. (2005). Perfil dos sujeitos gagos do Projeto em Fluência da Fala da Universidade de Ribeirão Preto. Revista Fono Atual, São Paulo, v.8, n.34, p.58-64.

FERRIOLLI, B. H. V. M. (2002). A análise de discurso como proposta clínica fonoaudiológica nos casos de disfluência da fala. Relato de um caso. In: MEIRA, I. (Org.). Tratando gagueira: diferentes abordagens. São Paulo: Cortez, p.67-78.

FRIEDMAN, S. (1986). Gagueira: origem e tratamento. Distúrbios da Comunicação, São Paulo, v.1, n.3, p.189-191.

. (1999). Fluência: normalidade e patologia. Distúrbios da Comunicação, São Paulo, v.11, n.1, p.131-136.

GELAMO, R. P. (2006). Organização prosódica e interpretação de canções: a frase entonacional em quatro diferentes interpretações de Na batucada da vida. 107f. Dissertação (Mestrado em Estudos Linguísticos) - Instituto de Biociências, Letras e Ciências Exatas, Universidade Estadual Paulista "Júlio de Mesquita Filho", São José do Rio Preto.

LEMOS, S. M. A.; CHIARI, B. M. (1995). Pausas plenas: sua ocorrência na estruturação de frases. Revista Pró-Fono, Barueri, v. 7, n.2, p.10-13.

MARCUSCHI, L. A. (!999). A hesitação. In: NEVES, M. H. M. Gramática do português falado: novos estudos. Campinas: UNICAMP/FAPESP, p.159-194.

MARTINS, V. O.; ANDRADE, C. R. F. A. Perfil evolutivo da fluência da fala de falantes do português brasileiro. Revista Pró-Fono, Barueri, v.20, n.1, p.7-12, 2008.

MERÇON, S. M. A.; NEMR, K. Gagueira e disfluência comum na infância: análise das manifestações clínicas nos seus aspectos qualitativos e quantitativos. Revista CEFAC, v.9, n.2, p. 174-179, 2007.

NASCIMENTO, J. C. (2005). Fenômeno hesitativo na linguagem: um olhar para a doença de Parkinson. 158f. Dissertação (Mestrado em Estudos Lingüísticos) - Instituto de Biociências, Letras e Ciências Exatas, Universidade Estadual Paulista "Júlio de Mesquita Filho", São José do Rio Preto.

. (2010). Uma perspectiva discursiva sobre a hesitação. 128 f. Tese (Doutorado em Estudos Lingüísticos) - Instituto de Biociências, Letras e Ciências Exatas, Universidade Estadual Paulista "Júlio de Mesquita Filho", São José do Rio Preto.

NASCIMENTO, J. C.; CHACON, L. (2006). Por uma visão discursiva do fenômeno da hesitação. Alfa, São Paulo, v.50, n.1, p.59-76.

. (2011). Um olhar enunciativo-discursivo sobre a hesitação em um sujeito com Doença de Parkinson. In: TFOUNI, L. V.; MONTE-SERRAT, D. M.; CHIARETTI, P. (Orgs.) A análise do discurso e suas interfaces. São Carlos: Pedro \& João Editores, pp.125-143.

OLIVEIRA, A. M. C. C.; RIBEIRO, I. M.; MERLO, S.; CHIAPPETTA, A. L. M. L. (2007). O que fonoaudiólogos e estudantes de fonoaudiologia entendem por fluência e disfluência. Revista CEFAC, v.9, n.1, p.40-46.

SCARPA, E. M. (1995). Sobre o sujeito fluente. Caderno de Estudos Lingüísticos, Campinas: v.29, p.163-184. 
Cadernos de ESTUDOS LINGüísTICOS (54.1) - Jan./Jun. 2012

SCHIEFER, A. M.; CHIARI, B. M.; BARBOSA, L. M. G. (1992). Orientação aos pais: uma proposta de atuação preventiva na fala de crianças disfluentes. Revista Pró-Fono, Barueri, vol. 4, n.1, p.03-06.

SILVEIRA, A. L. S. (1989). Considerações sobre a anamnese da gagueira. Distúrbios da Comunicação, São Paulo, v.3, n.1, p.67-70.

VIEIRA, R. C. R. (2009). Doença de Parkinson: deslizamentos do dizer marcados por hesitações em contexto fonético-fonológico recorrente, 106f. Dissertação (Mestrado em Estudos Lingüísticos) - Instituto de Biociências, Letras e Ciências Exatas, Universidade Estadual Paulista "Júlio de Mesquita Filho", São José do Rio Preto. 
